\title{
Ultrasound-targeted microbubble destruction-mediated Galectin-7-siRNA promotes the homing of bone marrow mesenchymal stem cells to alleviate acute myocardial infarction in rats
}

\author{
XIN WEI $^{1 *}$, YAN ZHENG $^{1 *}$, WEILIN ZHANG ${ }^{1}$, JING TAN $^{2}$ and HONG ZHENG $^{1}$ \\ ${ }^{1}$ Department of Ultrasound, People's Hospital of Deyang City, Deyang, Sichuan 618000; ${ }^{2}$ Department of Cardiology, \\ Guizhou Provincial People's Hospital, Guiyang, Guizhou 550002, P.R. China
}

Received November 29, 2019; Accepted October 19, 2020

DOI: $10.3892 /$ ijmm.2020.4830

\begin{abstract}
Bone marrow mesenchymal stem cells (BMSCs) are accepted as a form of cellular therapy to improve cardiac function following acute myocardial infarction (AMI). The present study was performed to investigate the synergistic effect of ultrasound-targeted microbubble destruction (UTMD)-mediated Galectin-7-small interfering (si)RNA with the homing of BMSCs for AMI. The rat model of AMI was established, followed by identification of BMSCs. Rats with AMI received BMSC transplantation, BMSC transplantation + UTMD + siRNA negative control, or BMSC transplantation + UTMD + Galectin-7-siRNA. The cardiac function, hemodynamics indexes, degree of myocardial fiber injury and expression of apoptosis-related proteins in myocardial tissues of rats were detected. The homing of BMSCs was observed, and the indexes of myocardial microenvironment and the TGF- $\beta /$ Smads pathway-related proteins in myocardial tissues were determined. AMI rats treated with UTMD-mediated Galectin-7-siRNA exhibited improved cardiac function and hemodynamics-related indices, decreased myocardial fiber injury and apoptotic cells, as well as enhanced homing ability of BMSCs, improved myocardial
\end{abstract}

Correspondence to: Dr Jing Tan, Department of Cardiology, Guizhou Provincial People's Hospital, 83 Zhongshan East Road, Nanming, Guiyang, Guizhou 550002, P.R. China

E-mail: tanjing0904@163.com

Dr Hong Zheng, Department of Ultrasound, People's Hospital of Deyang City, 173 Taishan North Road, Deyang, Sichuan 618000, P.R. China

E-mail: dydmqj2300192@163.com

*Contributed equally

Key words: acute myocardial infarction, ultrasound-targeted microbubble destruction, Galectin-7, homing, bone marrow mesenchymal stem cells, myocardial microenvironment, TGF- $\beta 1 /$ Smads signaling pathway microenvironment, and suppressed TGF- $\beta 1 /$ Smads pathway activation. In conclusion, the present study demonstrated that UTMD-mediated Galectin-7-siRNA treatment could enhance the homing ability of BMSCs, thus alleviating AMI in rats.

\section{Introduction}

Myocardial infarction (MI) results from oxygen deprivation after a block of one of the coronary artery branches together with sudden halt of blood flow and myocardial anoxia (1). MI is one of the primary causes of death worldwide and is characterized by vascular endothelial injury induced by inflammation, apoptosis, cardiac fibrosis and pathological remodeling (2), which contributes to high morbidity and mortality globally (3). Acute MI (AMI) can contribute to the enhancement of reactive oxygen along with activation of deleterious cellular signals, thereby elevating inflammatory cytokine expression in endothelial cells and inducing the infiltration of inflammatory cells to the infarct zone (4). Risk stratification and management of patients with AMI remains challenging, although great efforts have been made by numerous clinicians and researchers in the last decades (5). Therefore, a novel specific and highly-sensitive biomarker is urgently needed in order to provide early diagnosis of AMI and to identify potential regulatory targets of AMI.

Bone marrow mesenchymal stem cells (BMSCs) are a widely studied cellular therapy that can improve cardiac function after MI (6). An increasing number of regimens have been found for gene delivery to the heart, such as intrapericardial, intracoronary and direct myocardial injection (7). Novel gene therapies, especially non-invasive methods that are able to stimulate stem cell homing to the injured heart, can improve function by inducing regional perfusion along with tissue regeneration in the infarcted myocardium $(8,9)$. Recently, ultrasound-targeted microbubble destruction (UTMD) has been found to act as a novel approach of tissue-specific gene delivery that transfers nucleic acid drugs through the cavitation effect in a range of the microvasculature of target tissues, which is useful for local delivery and to evade biological barriers in tissues (10). It has been revealed that UTMD-mediated gene therapy alleviates myocardial perfusion and cardiac function 
in mice with MI (11). Although the capability of UTMD to induce histologically definable microlesions has been demonstrated in small animals, the effects of such microlesions on the heart have not yet been fully examined (12).

Galectin is a novel target associated with unfavorable prognosis in patients with heart failure. Elevated galectin levels are related to heart failure, and may be a primary regulator of cardiac remodeling with myocardial fibrosis (13). Galectin-7, as a member of galectin family, plays a role in various events related to the development of the pluristratified epithelium (14). It is also correlated with epithelial cell migration and plays a part in the re-epithelialization process of corneal and epidermal wounds (15). A previous study discovered that galectin-7 knockdown contributed to declined differentiation and elevated proliferation of keratinocytes (16). However, the role of galectin-7 in AMI remains unknown. Galectin-1 and galectin-3 are proposed to be involved in MI $(17,18)$. The role of galectin-7 has not been reported in MI, but galectin-7 can promote $\mathrm{CD}^{+} \mathrm{T}$ cell proliferation and $\mathrm{T}$ helper cell (Th) $1 / 2$ polarization by inhibiting the TGF $\beta / \mathrm{Smad} 3$ pathway (19), and galectin-7 plays a role in apoptosis by binding to Bcl-2 (20). Moreover, the TGF $\beta / \mathrm{Smad} 3$ pathway and apoptosis are involved in the process of MI (21). Hence, it is speculated that galectin-7 may play a role in MI. Therefore, the present study aimed to elucidate the synergistic effect of UTMD-mediated galectin-7-small interfering (si)RNA with the homing of BMSCs for AMI, along with its underlying mechanism, which could provide useful findings in the discovery of novel therapeutic targets of AMI.

\section{Materials and methods}

Ethics statement. Animal experiments were implemented in accordance with the Guide to the Management and Use of Laboratory Animals (22). The animal experiment protocols were approved by the Institutional Animal Care and Use Committee of People's Hospital of Deyang City (approval no. 20190075; Deyang, China). The rats were housed in a controlled environment, at a temperature of $22-24^{\circ} \mathrm{C}$ and $12 / 12 \mathrm{~h}$ light/dark cycles, with free access to standard rat food and water.

Experimental animals. A total of 84 healthy male Sprague-Dawley (SD) rats $(250 \pm 10 \mathrm{~g}, 6$ weeks old) and four SD rats (two male and two female, $100 \pm 5 \mathrm{~g}, 3$ weeks old) were acquired from The Sixth Affiliated Hospital of Sun Yat-sen University [license no. SYXK (Yue) 2018-0190; Guangzhou, China] and were fed under normal conditions.

Isolation, culture, identification and labeling of rat BMSCs. A total of four 3-week-old rats were anesthetized (intraperitoneal injection of $100 \mathrm{mg} / \mathrm{kg}$ pentobarbital) and sacrificed by cervical dislocation. The femur was separated under aseptic conditions. After washing, the bone marrow cavity was exposed after removal of both ends of the epiphysis. The bone marrow cavity was rinsed repeatedly with DMEM/F12 medium solution (Sigma Aldrich; Merck KGaA) containing $10 \%$ fetal bovine serum (FBS; Beijing Solarbio Science \& Technology Co., Ltd.). Bone marrow cells were collected and placed in Percoll separation solution (Beijing Solarbio Science
\& Technology Co., Ltd.). BMSCs were separated and purified by density gradient equilibrium centrifugation and adherent screening method (23). BMSCs were observed using an IX-70 inverted phase contrast microscope (Olympus Corporation).

BMSCs in the 3 rd passage were detached with $0.25 \%$ trypsin and fluorescein isothiocyanate (FITC)-conjugated antibodies against CD29 (cat. no. ab21845; 1:10), CD34 (cat. no. ab78165; 1:10), CD44 (cat. no. ab30405; 1:10) and CD45 (cat. no. ab27287; 1:10) (all purchased from Abcam) were added. The corresponding negative control (NC) was set for each tube and incubated for $45 \mathrm{~min}$ in the dark at $4^{\circ} \mathrm{C}$. After washing with phosphate buffered saline (PBS) three times, the BMSCs were centrifuged at $400 \mathrm{xg}$ for $5 \mathrm{~min}$ at $4^{\circ} \mathrm{C}$ and suspended with $50 \mu$ l PBS, following which they were analyzed with a BD FACSCanto ${ }^{\mathrm{TM}}$ II Flow Cytometer (BD Biosciences) and BD CellQuest ${ }^{\mathrm{TM}}$ Pro software (BD Biosciences).

An enhanced green fluorescence protein (EGFP) plasmid (3.0 $\mu \mathrm{g}$ per $1 \times 10^{4}$ cells/well) (Sigma-Aldrich; Merck KGaA) was transfected into BMSCs using Lipofectamine ${ }^{\circledR} 2000$ (Invitrogen; Thermo Fisher Scientific, Inc.) 2 days before cell transplantation. After transfection for $24 \mathrm{~h}$, the liquid was replaced and observed under a fluorescence microscope (Olympus Corporation). After detaching the cells with $0.25 \%$ trypsin, DMEM-F12 medium was added. A cell suspension of $5 \times 10^{6}$ cells $/ \mathrm{ml}$ was prepared and transplanted for use.

Osteogenic and adipogenic induction and identification of rat BMSCs. BMSCs were incubated at $37^{\circ} \mathrm{C}$ with $5 \% \mathrm{CO}_{2}$, and $1 \mu \mathrm{mol} / 1$ dexamethasone, $10 \mu \mathrm{mol} / 1 \beta$-glycerophosphate, $50 \mathrm{mg} / \mathrm{l}$ vitamin, and L-DMEM (Beijing Solarbio Science \& Technology Co., Ltd.) containing 10\% FBS were added $48 \mathrm{~h}$ later to induce osteogenesis, and the medium was renewed once every 2 to 3 days. The control group was cultured in L-DMEM without the aforementioned inducers. The method of adipogenic induction was the same, but the culture was supplemented with $1 \mu \mathrm{mol} / 1$ dexamethasone, $0.5 \mathrm{mmol} / 1$ 3-isobutyl-1 methylxanthine (IBMX), $10 \mathrm{mg} / 1$ insulin and H-DMEM (Beijing Solarbio Science \& Technology Co., Ltd.) with $10 \%$ FBS. The control group was cultured in H-DMEM without the aforementioned inducers.

The coverslips of the cells were immersed in PBS for $1 \mathrm{~min}$ three times, fixed with $4 \%$ formaldehyde for $15 \mathrm{~min}$ at $37^{\circ} \mathrm{C}$, immersed in PBS for 3 min three times, stained with $0.2 \%$ Alizarin red (Beyotime Institute of Biotechnology) for 5-30 min at $37^{\circ} \mathrm{C}$, followed by washing with PBS and microscopic examination under a light microscope (BX51; Olympus Corporation).

The coverslips were fixed with formaldehyde-calcium for $10 \mathrm{~min}$ at $37^{\circ} \mathrm{C}$, washed with distilled water; rinsed with $60 \%$ isopropanol, stained with oil red $\mathrm{O}$ (Beyotime Institute of Biotechnology) at $37^{\circ} \mathrm{C}$ for $10 \mathrm{~min}$, differentiated with $60 \%$ isopropanol, followed by washing with distilled water, hematoxylin counterstaining at $37^{\circ} \mathrm{C}$ for $10 \mathrm{~min}$, rinsing with water and microscopic examination under a light microscope.

Establishment of AMI rat models and identification. The rats were anesthetized with an intraperitoneal injection of $2 \%$ pentobarbital sodium $(40 \mathrm{mg} / \mathrm{kg}$; Sigma-Aldrich; Merck KGaA) and laid down on the operating table. The AMI rat model was established by ligating the left anterior 
descending branch of the coronary artery (24). The electrocardiogram (Chengdu Medical Instrument Factory) was detected before the coronary artery ligation and 7 days after the model was established.

Animal grouping. On the 7th day after the establishment of the AMI model, rats were transplanted with BMSCs and divided into five groups ( $\mathrm{n}=15 /$ group) according to different treatments: i) Sham group, rats with thoracotomy and without ligation of the left anterior descending branch of the coronary artery; ii) AMI group, AMI rats with no treatments; iii) BMSC group, AMI rats injected with $5 \times 10^{6}$ labeled BMSCs via the caudal vein; iv) BUTMD + siRNA NC group, BMSC transplantation, UTMD and siRNA NC; v) BUTMD + Galectin-7-siRNA group, BMSC transplantation, UTMD and Galectin-7-siRNA. For the BUTMD + siRNA NC group, siRNA NC $(100 \mu \mathrm{M}$; Sigma-Aldrich; Merck KGaA) was mixed with sulphur hexafluoride microbubbles (Bracco Suisse SA) and incubated for $30 \mathrm{~min}$ at $25^{\circ} \mathrm{C}$ to construct siRNA NC encapsulated in sulphur hexafluoride microbubbles; then the siRNA NC encapsulated in SF6 microbubbles was added to EGFP-labeled BMSCs and the mixture was injected into rats via the tail vein. Ultrasound (frequency $1 \mathrm{M} \mathrm{Hz}$, power $2 \mathrm{~W} / \mathrm{cm}^{2}$ ) was immediately irradiated to the anterior wall of the left ventricle of rats for $120 \mathrm{sec}$. For the BUTMD + Galectin-7-siRNA group, after incubation of Galectin-7-siRNA (100 $\mu \mathrm{M}$; Sigma-Aldrich; Merck KGaA) with microvesicles at $25^{\circ} \mathrm{C}$ for $30 \mathrm{~min}$, the subsequent steps were the same as the BUTMD + siRNA NC group. Galectin-7-siRNA sequences were sense, 5'-CAUCCGAGG UUGUCUUCAACA-3' and antisense, 5'-UUGAAGACAACC UCGGAUGUG-3'.

Echocardiographic evaluation and hemodynamic monitoring. Four weeks after transplantation of the BMSCs, rats were anesthetized with $30 \mathrm{mg} / \mathrm{kg}$ pentobarbital sodium, and the left ventricular end diastolic diameter (LVEDd) and left ventricular end systolic diameter (LVESd) were detected using a Vivid-7 color Doppler ultrasound scanner (GE Healthcare), and the left ventricular ejection fraction (EF) was calculated using the following formula: $\mathrm{EF}=$ stroke volume/end-diastolic volume $\mathrm{x} 100 \%$. After the cardiac color Doppler ultrasound, a catheter filled with heparin saline was placed in the right common carotid artery to the left ventricle, and the left ventricular systolic pressure (LVSP), left ventricular end-diastolic pressure (LVEDP) and left ventricular maximal rate of rise and fall ( $\pm \mathrm{dp} / \mathrm{dtmax})$ were recorded using a multi-conductive physiological recorder (Chengdu Medical Instrument Factory).

Tissue specimen collection. The heart of the rats was examined using ultrasound, and then the rats were euthanized by an intraperitoneal injection of $800 \mathrm{mg} / \mathrm{kg}$ pentobarbital sodium (25). The myocardial tissues around the infarct area were collected. The myocardial tissues of six rats in each group were fixed with $4 \%$ paraformaldehyde at $25^{\circ} \mathrm{C}$ for $24 \mathrm{~h}$, and then the paraffin-embedded tissues were sliced $(5 \mu \mathrm{m})$ for histological staining. The myocardial tissues of six rats in each group were made into tissue homogenate. The myocardial tissue sections $(5 \mu \mathrm{m})$ of the remaining three rats in each group were frozen at $-20^{\circ} \mathrm{C}$.
$H \& E$ staining. Paraffin-embedded sections were routinely dewaxed and dehydrated, stained for $3 \mathrm{~min}$ with hematoxylin at $25^{\circ} \mathrm{C}$ (Beijing Solarbio Science \& Technology Co., Ltd.), differentiated for $15 \mathrm{sec}$ with $1 \%$ hydrochloric acid alcohol, stained with eosin (Beijing Solarbio Science \& Technology Co., Ltd.) at $25^{\circ} \mathrm{C}$ for 2 min and observed under an optical microscope (Olympus Corporation).

Masson staining. Paraffin-embedded sections were routinely dewaxed, stained with the Masson's Trichrome Stain kit (Beijing Solarbio Science \& Technology Co., Ltd.), according to the manufacturer's protocols, and finally, myocardial infarct size was calculated using Image ProPlus 6.0 (Media Cybernetics, Inc.).

Terminal deoxynucleotidyl transferase-mediated dUTP nick end-labeling (TUNEL) staining. Paraffin-embedded sections were routinely dewaxed, and then stained with the TUNEL Apoptosis Detection kit (Shanghai Yeasen Biotechnology Co., Ltd.), according to the instructions of the manufacturer. Finally, a few drops of $100 \mathrm{ng} / \mathrm{ml}$ 4',6-Diamidino-2-phenylindole (DAPI; Beyotime Institute of Biotechnology) was added for nuclear staining at room temperature for $10 \mathrm{~min}$, and TUNEL-positive cells were captured under a fluorescence microscope (BX51; Olympus Corporation). At least three sections were observed in each tissue, and three visual fields were randomly selected for statistical analysis.

Frozen sections to observe the homing of BMSCs. Frozen sections were sealed in a sealing liquid containing DAPI (Beyotime Institute of Biotechnology) and imaged under a laser confocal fluorescence microscope (TCS SP5; Leica Microsystems GmbH).

Reverse transcription-quantitative $(R T-q) P C R$. Total RNA was extracted from the tissue homogenate of each group using a TRIzol ${ }^{\circledR}$ kit (Beijing Dingguo Changsheng Biotechnology Co., Ltd.). RNA was reverse transcribed into cDNA at $42^{\circ} \mathrm{C}$ for 60 min using the ReverTra Ace ${ }^{\mathrm{TM}}$ qPCR RT Master Mix kit (Toyobo Life Science). PCR was conducted using SYBR $^{\circledR}$ Premix Ex Taq ${ }^{\mathrm{TM}}$ II (Takara Bio, Inc.). Thermocycling conditions were as follows: $95^{\circ} \mathrm{C}$ for $10 \mathrm{~min} ; 35$ cycles of $94^{\circ} \mathrm{C}$ for $60 \mathrm{sec}, \mathrm{Tm} 56^{\circ} \mathrm{C}, 72^{\circ} \mathrm{C}$ for $60 \mathrm{sec}$; and then, $72^{\circ} \mathrm{C}$ for $10 \mathrm{~min}$. $\beta$-actin was used as the loading control. The primer sequences used are shown in Table I, and the mRNA expression was analyzed using the $2^{-\Delta \Delta \mathrm{Cq}}$ method (26).

Western blot analysis. The protein was extracted using RIPA buffer (Thermo Fisher Scientific, Inc.). Total protein concentration of tissue homogenate was detected using a bicinchoninic acid detection kit (Pierce; Thermo Fisher Scientific, Inc.). The proteins (30 $\mu \mathrm{g} /$ well) were separated via sodium dodecyl sulfate polyacrylamide gel electrophoresis (Beyotime Institute of Biotechnology) on a $10 \%$ gel, and then transferred onto polyvinylidene difluoride membranes. Next, the membranes were blocked for $1 \mathrm{~h}$ with $5 \%$ skimmed milk at $37^{\circ} \mathrm{C}$, and then incubated at $4^{\circ} \mathrm{C}$ overnight with primary antibodies against: Galectin-7 (cat. no. ab206435; 1:1,000), Bcl-2 (cat. no. ab182858; 1:2,000), Bax (cat. no. ab32503; 1:1,000), stromal cell-derived factor 1 (SDF-1; cat. no. ab25117; 1:1,000), vascular endothelial 
Table I. Primer sequences.

\begin{tabular}{ll}
\hline Gene & \multicolumn{1}{c}{ Primer sequences $\left(5^{\prime} \rightarrow 3^{\prime}\right)$} \\
\hline SDF-1 & F: TTGCCAGCACAAAGACACTCC \\
& R: CTCCAAAGCAAACCGAATACAG \\
VEGF & F: GTGAGCCTTGTTGTTCAGCG \\
& R: GACGGTGACGATGGTGG \\
VCAM-1 & F: GTCGTGGTCAGCCCCTCCTC \\
& R: CAGCCTGGTTAATCCCTTCACAC \\
IL-1 $\beta$ & F: CTTCGGGCTCTCCACCTCA \\
TGF- $\beta 1$ & R: AATCGCTTTTCCATCTTCCTCTT \\
& F: AGGGCTACCATGCCAACTTC \\
Smad3 & R: CCACGTAGTAGACGATGGGC \\
& F: AGACACCAGTGATACCTCCA \\
Smad7 & R: CCAGCGGGGAAGTTAGTGTT \\
& F: CAGGCTCCAGAAGAAGTTGG \\
$\beta$-actin & R: AGTTCAACGGCACAGTCAAG \\
& F: TGGCTGGCCGGGACCTGACTGA \\
& R: CGCGCCGTGGCCATCTCCTG
\end{tabular}

F, forward; R, reverse; SDF-1, stromal cell-derived factor 1; VEGF, vascular endothelial growth factor; VCAM-1, vascular cell adhesion molecule-1; IL-1 $\beta$, interleukin-1 $\beta$; cTnI, cardiac troponin I; $\alpha$-MHC, $\alpha$-myosin heavy chain; TGF- $\beta 1$, transforming growth factor- $\beta 1$.

growth factor (VEGF; cat. no. ab32152; 1:1,000), vascular cell adhesion molecule-1 (VCAM-1; cat. no. ab134047; $1: 2,000$ ), interleukin (IL)-1 $\beta$ (cat. no. ab2105; 1:1,000), cardiac troponin I (cTnI; cat. no. ab47003; 1:1,000), $\alpha$-myosin heavy chain ( $\alpha$-MHC; cat. no. ab180779; $1: 2,000$ ), collagen I (cat. no. ab6308; $1 \mu \mathrm{g} / \mathrm{ml}$ ), transforming growth factor- $\beta 1$ (TGF- $\beta 1$; cat. no. ab179695; $1: 1,000)$, Smad3 (cat. no. ab40854; 1:1,000), Smad7 (cat. no. ab216428; $1: 1,000)$ and glyceraldehyde phosphate dehydrogenase (GAPDH; cat. no. ab8245; 1:1,000) (all purchased from Abcam). Following which, membranes were incubated with a horseradish peroxidase-labeled anti-rabbit IgG secondary antibody (cat. no. ab205718; 1:2,000; Abcam) and incubated for $1 \mathrm{~h}$ at $25^{\circ} \mathrm{C}$. Then, membranes were developed with a chemiluminescence reagent (Thermo Fisher Scientific, Inc.). GAPDH was used as the internal reference. Relative protein expression was expressed as the ratio of the gray value of the target protein band to that of the internal reference. The gray value of the target band was analyzed using ImageJ version 1.8.0 software (National Institutes of Health).

Enzyme-linked immunosorbent assay (ELISA). Following centrifugation of the tissue homogenate at $4^{\circ} \mathrm{C}$ and $1,200 \times \mathrm{g}$ for $5 \mathrm{~min}$, the levels of TGF- $\beta 1$ (cat. no. m1002856) and cTnI (cat. no. m1059111) in the supernatant were measured using ELISA kits (Shanghai Enzyme-linked Biotechnology Co., Ltd.), according to the manufacturer's instructions.

Statistical analysis. The independent experiments were repeated three times. Data analyses were performed using
SPSS 21.0 software (IBM Corp.). The measurement data conforming to the normal distribution after verification using a Kolmogorov-Smirnov test were depicted as mean \pm standard deviation. One-way or two-way analysis of variance (ANOVA) was performed for comparisons among multiple groups, and Tukey's multiple comparisons test was applied for pairwise comparisons following ANOVA. $\mathrm{P}<0.05$ was considered to indicate a statistically significant difference.

\section{Results}

Rat AMI model and BMSC identification. Compared with the sham-operated rats, the electrocardiogram of the rats with AMI showed an upward ST-segment elevation and merged with a $\mathrm{T}$ wave into a one-way curve (Fig. 1A). H\&E staining showed that the myocardial fibrous tissue of the rats with AMI was disordered and broken, and the nucleus was ruptured compared with the sham-operated rats (Fig. 1B). These results indicated that the rat model of AMI was successfully established.

The BMSCs cultured for $24 \mathrm{~h}$ were spherical under a microscope, and BMSCs cultured for 7 days were long fusiform (Fig. 1C). Flow cytometry results showed that CD29 and CD44 were positively expressed on the surface of BMSCs, whereas CD34 and CD45 showed negative expression (Fig. 1D). BMSCs transfected with EGFP showed green fluorescence under a fluorescence microscope, confirming the successful transfection of EGFP (Fig. 1E). Finally, the BMSCs were cultured under osteogenic and adipogenic inductive environments and the results revealed that BMSCs had multilineage differentiation ability (Fig. 1F and G). These results indicated that BMSCs were successfully cultured.

BMSC transplantation improves AMI in rats. After BMSC transplantation, the cardiac function and hemodynamics of rats in the BMSC group were significantly improved compared with that of the AMI group ( $\mathrm{P}<0.01$; Fig. $2 \mathrm{~A}$ and $\mathrm{B}$ ). The results of pathological examination indicated that the myocardial fiber injury of rats was reduced $(\mathrm{P}<0.01$; Fig. $2 \mathrm{C}$ and D) and cardiomyocyte apoptosis rate was decreased after BMSC transplantation, but there was still a notable difference between the BMSCs group and the sham-operated group $(\mathrm{P}<0.01$; Fig. 2E and F). The green fluorescence in the myocardial tissues of rats in the BMSC group increased significantly $(\mathrm{P}<0.01$; Fig. 2G). These results indicated that BMSCs notably improved AMI injury in rats.

UTMD-mediated Galectin-7-siRNA promotes the homing of BMSCs to alleviate AMI in rats. It has been reported that Galectin-7 promotes CD4 ${ }^{+} \mathrm{T}$ cell proliferation and Th1/2 cell polarization by inhibiting the TGF $\beta / \mathrm{Smad} 3$ pathway (19), and Galectin-7 can play a role in apoptosis via binding to Bcl-2 (20). The TGF $\beta / S m a d 3$ pathway and apoptosis are involved in the process of MI (21). Myocardial cells were transfected with Galectin-7-siRNA to decrease Galectin-7 expression. To verify the specificity of Galectin-7-siRNA, the mRNA levels of Galectin-1, Galectin-3 and Galectin-7 were detected using RT-qPCR. The results showed that the expression levels of Galectin-3 and Galectin-1 were not affected by Galectin-7-siRNA, and Galectin-7 expression was significantly 
A
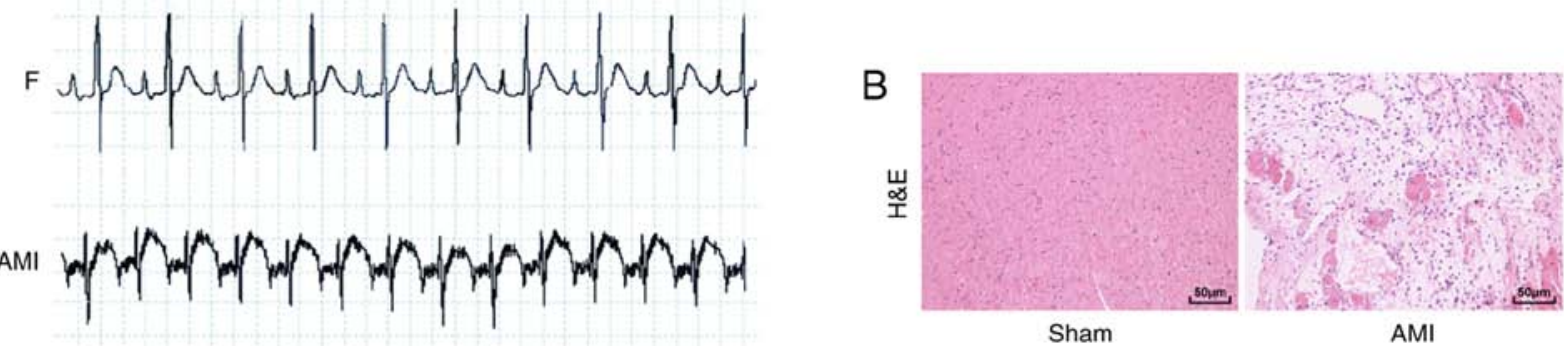

D

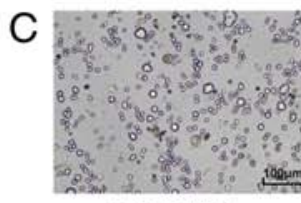

$24 \mathrm{~h}$ BMSCs

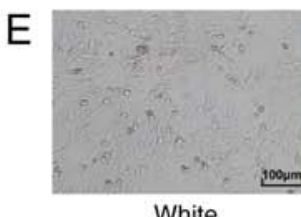

White

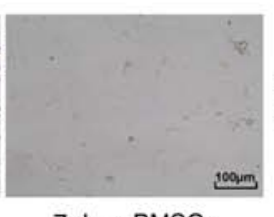

7 days BMSCs
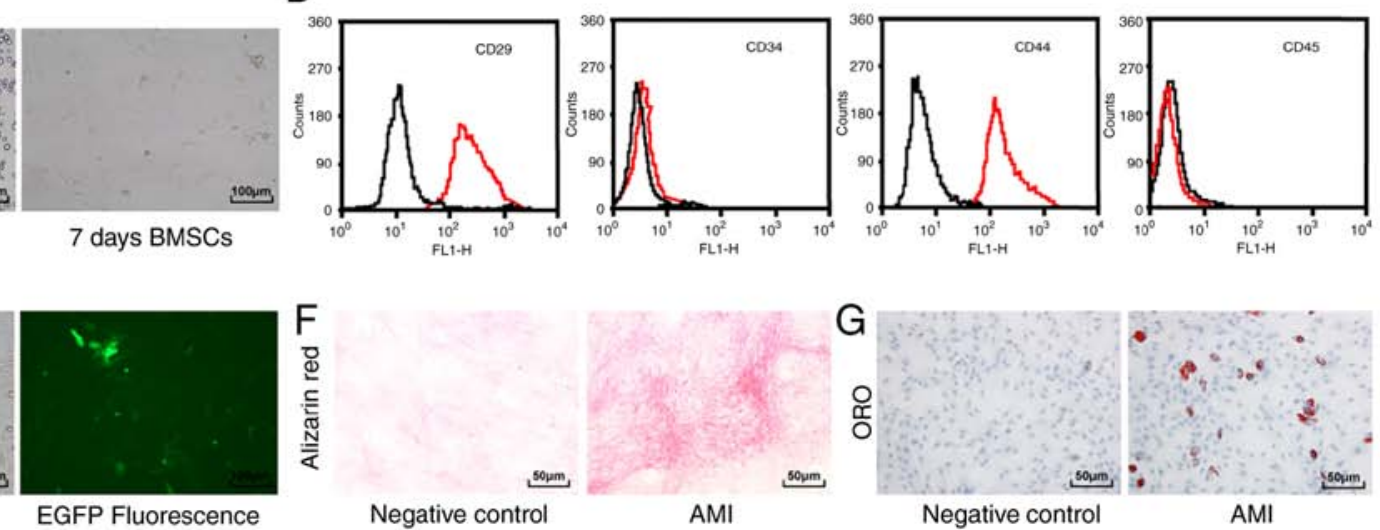

Figure 1. Rat AMI model and BMSC identification. (A) Electrocardiogram was used to detect changes in the heart's electrical activity before and after AMI in rats ( $\mathrm{n}=12$ /group). (B) Detection of myocardial tissue injury in rats ( $\mathrm{n}=6 /$ group) using H\&E staining (magnification, $\mathrm{x} 200 ;$ scale bar, $50 \mu \mathrm{m}$ ). (C) Observation of BMSC morphology using an inverted phase contrast microscope (magnification, x100; scale bar, $100 \mu \mathrm{m}$ ). (D) Flow cytometry analysis of BMSC surface markers. The black line in the figure represents the control IgG, and red line represents the surface markers. (E) Observation of EGFP-labeled BMSCs under a fluorescence microscope (magnification, x100; scale bar, $100 \mu \mathrm{m}$ ). (F) Alizarin red staining of BMSCs (magnification, x200; scale bar, 50 $\mu \mathrm{m}$ ). (G) ORO staining of BMSCs (magnification, x200; scale bar, $50 \mu \mathrm{m}$ ). AMI, acute myocardial infarction; BMSC, bone marrow mesenchymal stem cell; H\&E, hematoxylin and eosin; EGFP, enhanced green fluorescence protein; ORO, oil red O.

reduced $(\mathrm{P}<0.01$; Fig. 3A). Galectin-7 expression of rats in the BUTMD+Galectin-7-siRNA group was significantly decreased compared with that of the BMSC group ( $\mathrm{P}<0.01$; Fig. $3 \mathrm{~B})$. Subsequently, it was found that UTMD could promote the promoting effect of BMSCs on MI (BUTMD + siRNA NC), and UTMD + Galectin-7-siRNA group showed the most obvious effect $(\mathrm{P}<0.01$; Fig. 3C and D). Compared with the BMSCs group, rats in the BUTMD+Galectin-7-siRNA group alleviated the degree of myocardial injury $(\mathrm{P}<0.01$; Fig. $3 \mathrm{E}$ and $\mathrm{F})$, decreased the number of myocardial apoptotic cells $(\mathrm{P}<0.01$; Fig. 3G), enhanced Bcl-2 and reduced Bax expression $(\mathrm{P}<0.01$; Fig. $3 \mathrm{H})$, and increased the number of homing BMSCs in the myocardial tissues $(\mathrm{P}<0.01$; Fig. 3I). These results suggested that UTMD-mediated Galectin-7-siRNA had improved efficacy compared with BMSCs or UTMD treatment.

UTMD-mediated Galectin-7-siRNA improves the myocardial microenvironment. The related indexes of myocardial microenvironment in rats were detected. Relative to the sham-operated rats, the AMI rats presented elevated expression levels of SDF-1, VEGF, VCAM-1 and IL- $1 \beta$, increased cTnI and collagen I protein, and decreased $\alpha$-MHC protein. Compared with the AMI group, UTMD-mediated Galectin-7-siRNA notably promoted the expression levels of SDF-1, VEGF, VCAM-1, IL- $1 \beta$ and $\alpha$-MHC, and decreased levels of cTnI and collagen I in rat myocardial tissues (all $\mathrm{P}<0.05$; Fig. 4A-D). These results suggested that the combined treatment with UTMD-mediated
Galectin-7-siRNA can improve the myocardial microenvironment of rats.

UTMD-mediated Galectin-7-siRNA suppresses the TGF- $\beta /$ Smad signaling pathway. To further explore the downstream mechanism of the combined treatment group in MI, the expression levels of TGF- $\beta /$ Smads pathway-related proteins were detected in the rat myocardium. The mRNA and protein levels of TGF- $\beta 1$ and Smad3 in rats with AMI significantly increased, whereas the mRNA and protein levels of $\mathrm{Smad} 7$ decreased compared with the sham-operated rats. In rats treated with UTMD-mediated Galectin-7-siRNA, the levels of TGF- $\beta 1$ and Smad3 in myocardial tissue homogenate were significantly reduced, and the mRNA and protein levels of Smad7 significantly increased, compared with AMI rats (all $\mathrm{P}<0.05$; Fig. 5A-C). Overall, these results suggested that the combined treatment group relieved AMI via inhibiting the TGF- $\beta /$ Smads pathway.

\section{Discussion}

Stem cell transplantation is an effective method of treating MI (27). However, several limitations have been found in previous methods of in vitro transplantation of stem cells (28). Besides, the homing of exogenous BMSCs does not reach the infarcted areas efficiently, which limits their ability to improve cardiac function (29). Therefore, the present 


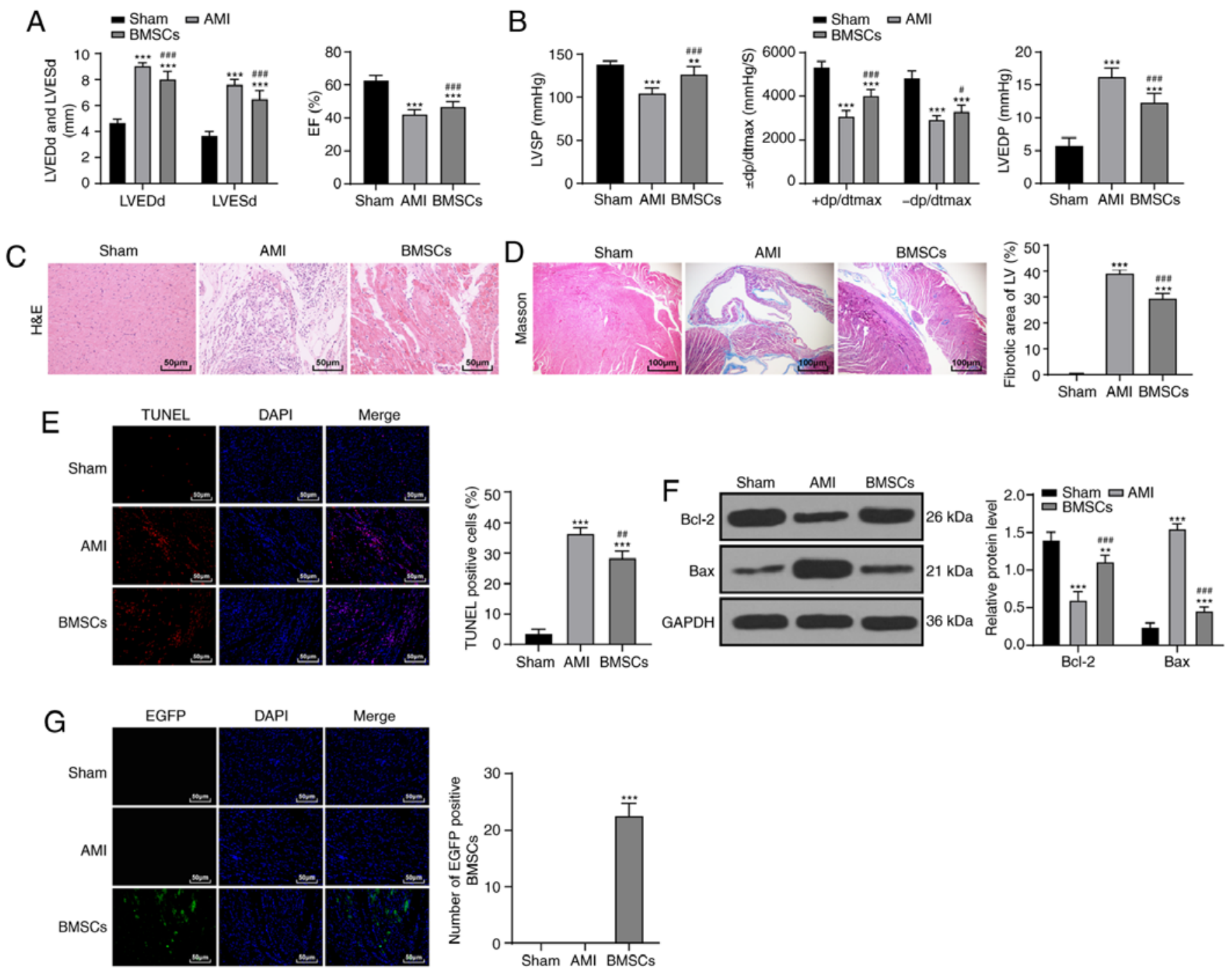

Figure 2. BMSC transplantation improves AMI in rats. (A) Detection of cardiac function indices in rats ( $\mathrm{n}=15 /$ group). (B) Hemodynamic determination in rats ( $\mathrm{n}=15 /$ group). (C) The morphology of myocardial tissue in each group ( $\mathrm{n}=6 /$ group) was observed with H\&E staining (magnification, $\mathrm{x} 200$; scale bar, $50 \mu \mathrm{m}$ ). (D) Observation of myocardial fibers in each group ( $\mathrm{n}=6$ /group) via Masson staining (magnification, $\mathrm{x} 400$; scale bar, $100 \mu \mathrm{m}$ ). (E) Detection of apoptosis in rats in each group ( $\mathrm{n}=6 /$ group) via TUNEL staining (magnification, $\mathrm{x} 400$; scale bar, $50 \mu \mathrm{m}$ ). (F) Detection of Bcl-2 and Bax protein expression by western blot analysis (n=6/group). (G) Observation of BMSC homing ability in rats ( $\mathrm{n}=3 /$ group) using fluorescence microscopy (magnification, $\mathrm{x} 400$; scale bar, $50 \mu \mathrm{m}$ ). Data in panels A (right), B (right/left), D, E and G were analyzed using one-way ANOVA, and data in panels A (left), B (middle) and F were analyzed using two-way ANOVA, followed by Tukey's multiple comparisons test. ${ }^{* *} \mathrm{P}<0.01$ and ${ }^{* * * *} \mathrm{P}<0.001$ vs. Sham group; ${ }^{*} \mathrm{P}<0.05,{ }^{\# \#} \mathrm{P}<0.01$ and ${ }^{\# \# \#} \mathrm{P}<0.001$ vs. AMI group. AMI, acute myocardial infarction; BMSC, bone marrow mesenchymal stem cell; H\&E, hematoxylin and eosin; TUNEL, transferase-mediated deoxyuridine triphosphate-biotin nick end labeling; LVEDd, left ventricular end diastolic diameter; LVESd, left ventricular end systolic diameter; EF, ejection fraction; LVSP, left ventricular systolic pressure; LVEDP, left ventricular end-diastolic pressure; \pm dp/dtmax, left ventricular maximal rate of rise and fall; LV, left ventricle; EGFP, enhanced green fluorescence protein.

study was conducted to elucidate the synergistic effect of UTMD-mediated Galectin-7-siRNA with the homing of BMSCs for AMI.

One of the most significant findings of the present study was that following BMSC transplantation, AMI rats exhibited improved cardiac function and left ventricular hemodynamics-related indices, and reduced myocardial fiber damage, myocardial infarct size and apoptotic cells. BMSCs are useful in the treatment of various diseases and injuries, including intervertebral disc degeneration and diabetic nephropathy, due to their multipotent differentiation and immunomodulatory functions $(30,31)$. SDF-1 and its specific receptor $\mathrm{C}-\mathrm{X}-\mathrm{C}$ chemokine receptor type 4 (CXCR-4) have been reported to play significant roles in adhesion, migration and survival of BMSCs to targeted tissues $(32,33)$. Strategies to increase the homing of infused stem cells consist of modifying SDF-1 levels and CXCR-4 receptor levels in host tissues (34). The homing process of BMSCs involves attachment to vascular endothelial cells, chemotactic response by interactions between the chemokine-chemokine receptor, as well as transendothelial migration into the parenchyma $(35,36)$. Meanwhile, it has been revealed that inflammatory cytokines and certain adhesion molecules, including P-selecin and VCAM-1, are also essential components implicated in the migration of stem cells to the inflamed sites (37-39).

To the best of our knowledge, relatively little is known concerning the role of Galectin-7 in AMI at present, and the present study was the first to show that AMI rats treated 


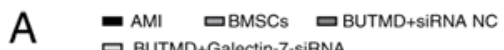

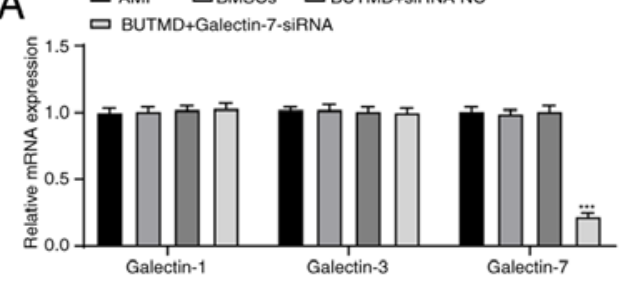

B

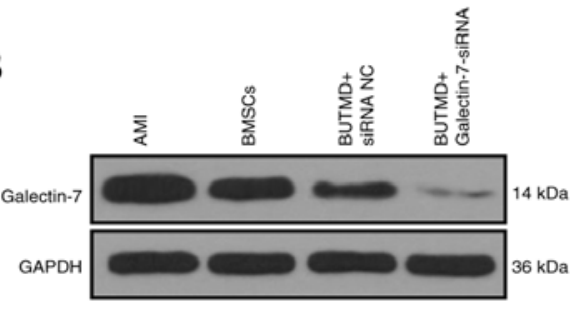

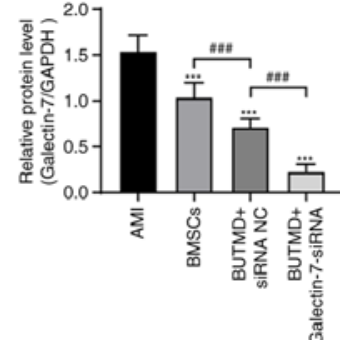

- AMI -BMSCS曰 BUTMD+SIRNA NC - BUTMD+Galectin-7-siRNA

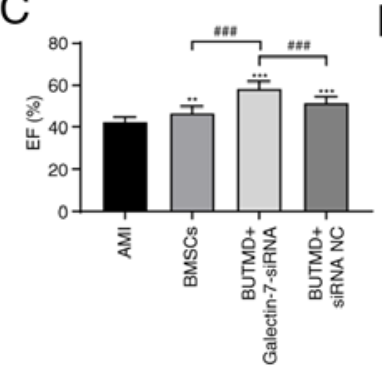

D
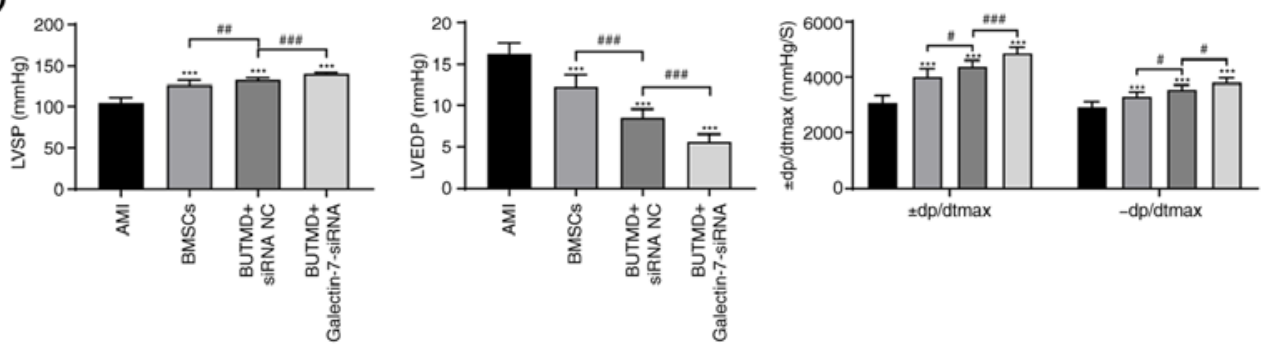

$\mathrm{E}$
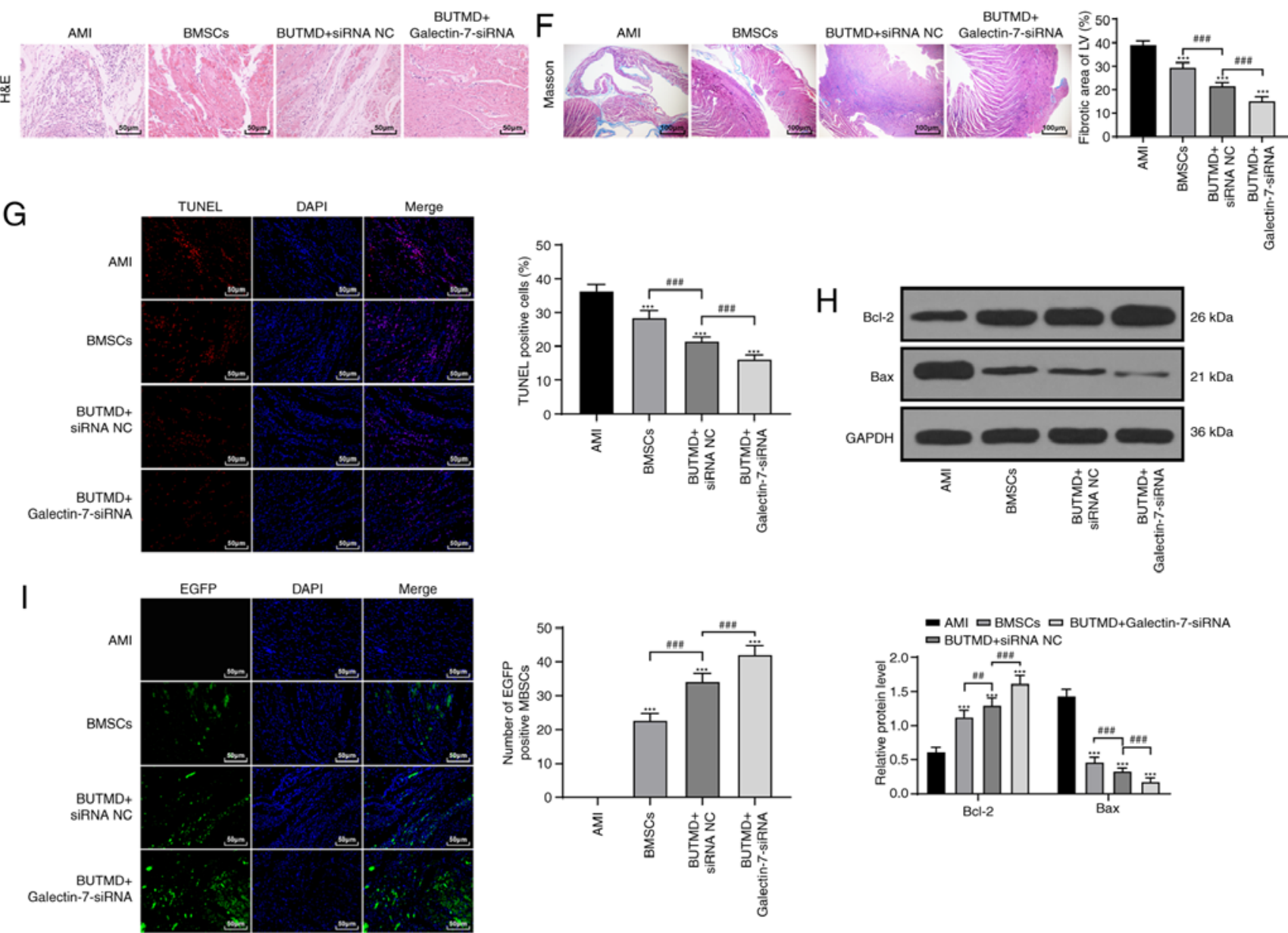

Figure 3. UTMD-mediated Galectin-7-siRNA promotes the homing of BMSCs to alleviate AMI in rats. (A) siRNA transfection efficiency was verified by reverse transcription-quantitative PCR (n=6/group). (B) Galectin-7 protein expression was detected by western blotting ( $\mathrm{n}=6 / \mathrm{group})$. (C) Detection of EF ( $\mathrm{n}=15$ /group). (D) Hemodynamic examination ( $\mathrm{n}=15 /$ group). (E) Observation of myocardium histomorphology using H\&E staining ( $\mathrm{n}=6 / \mathrm{group}$; magnification, $\mathrm{x} 200$; scale bar, $50 \mu \mathrm{m})$. (F) Observation of myocardial fibers via Masson staining (n=6/group; magnification, $\mathrm{x} 400$; scale bar, $100 \mu \mathrm{m})$. (G) Detection of apoptosis in rats of each group ( $\mathrm{n}=6 /$ group) via TUNEL staining (magnification, $\mathrm{x} 400$; scale bar, $50 \mu \mathrm{m}$ ). (H) Detection of Bcl-2 and Bax protein expression via western blotting, $(\mathrm{n}=6 /$ group). (I) Observation of BMSC homing in rats (n=3/group) using fluorescence microscopy (magnification, $\mathrm{x} 400$; scale bar, $50 \mu \mathrm{m}$ ). Data in panels B, C, D (left/middle), F, G and I were analyzed using one-way ANOVA, and data in panels A, D (right) and H were analyzed using two-way ANOVA, followed by Tukey's multiple comparisons test. ${ }^{* *} \mathrm{P}<0.01$ and ${ }^{* * *} \mathrm{P}<0.001$ vs. AMI group; ${ }^{\#} \mathrm{P}<0.05,{ }^{\# \#} \mathrm{P}<0.01$ and ${ }^{\# \# "} \mathrm{P}<0.001$ vs. indicated groups. UTMD, ultrasound-targeted microbubble destruction; siRNA, small interfering RNA; AMI, acute myocardial infarction; BMSC, bone marrow mesenchymal stem cell; H\&E, hematoxylin and eosin; TUNEL, transferase-mediated deoxyuridine triphosphate-biotin nick end labeling; EF, ejection fraction; LVSP, left ventricular systolic pressure; LVEDP, left ventricular end-diastolic pressure; $\pm \mathrm{dp} / \mathrm{dtmax}$, left ventricular maximal rate of rise and fall; NC, negative control; BUTMD, BMSCs + UTMD; LV, left ventricle; EGFP, enhanced green fluorescence protein. 

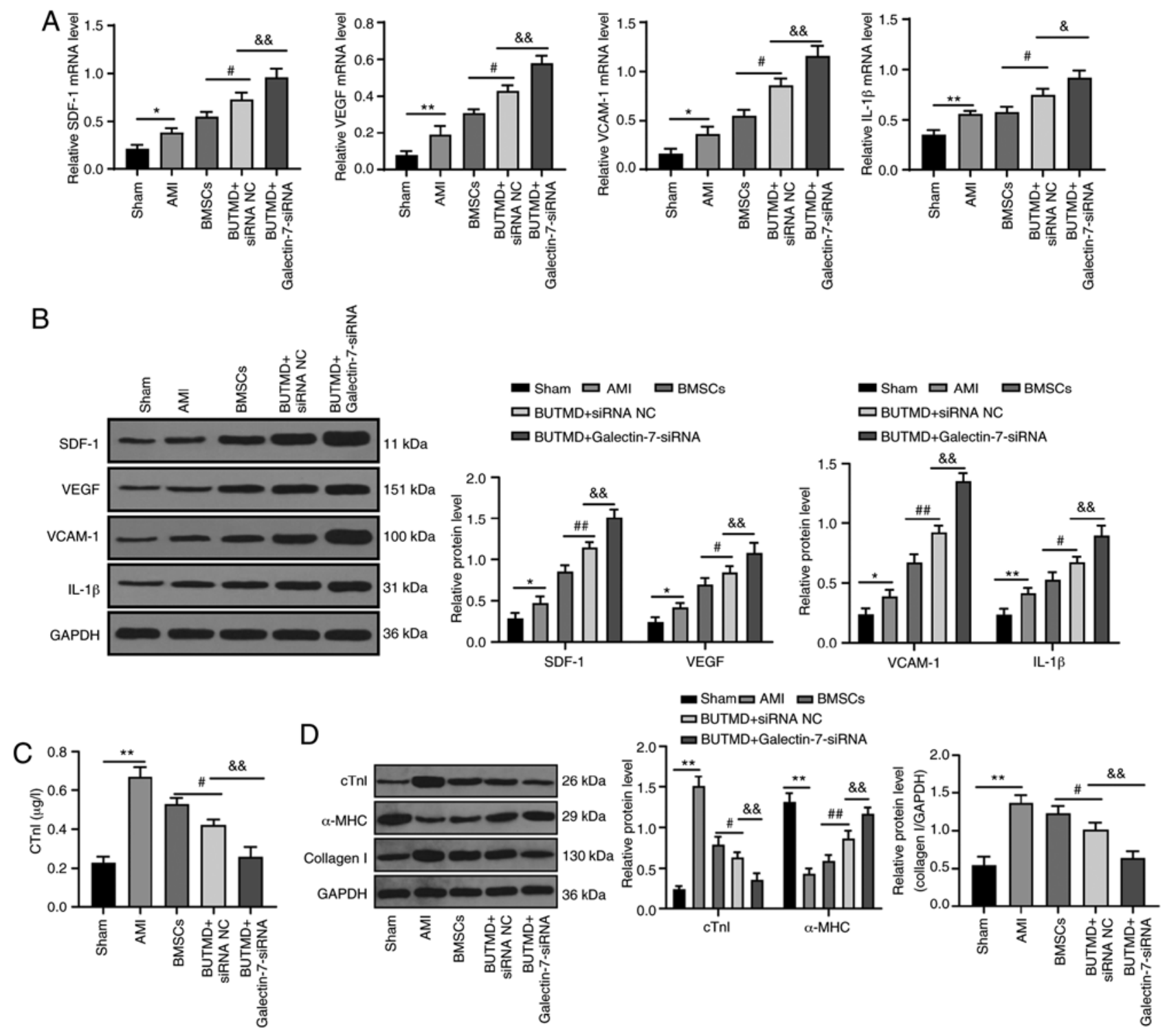

Figure 4. UTMD-mediated Galectin-7-siRNA improves the myocardial microenvironment. (A) Detection of mRNA expression levels of SDF-1, VEGF, VCAM-1 and IL-1 $\beta$ via reverse transcription-quantitative PCR. (B) Detection of protein expression levels of SDF-1, VEGF, VCAM-1 and IL-1 $\beta$ by western blot analysis. (C) cTnI protein expression was measured using ELISA. (D) cTnI, $\alpha$-MHC and collagen I protein expression levels were detected using western blotting ( $\mathrm{n}=6$ /group). Data in panels A, C and D (right) were analyzed using one-way ANOVA, and data in panels B and D (left) were analyzed using two-way ANOVA, followed by Tukey's multiple comparisons test. ${ }^{*} \mathrm{P}<0.05$ and ${ }^{* *} \mathrm{P}<0.01 ;{ }^{*} \mathrm{P}<0.05$ and ${ }^{\# \#} \mathrm{P}<0.01 ;{ }^{\&} \mathrm{P}<0.05$ and ${ }^{\text {\&\&}} \mathrm{P}<0.01$. UTMD, ultrasound-targeted microbubble destruction; siRNA, small interfering RNA; SDF-1, stromal cell-derived factor 1; VEGF, vascular endothelial growth factor; VCAM-1, vascular cell adhesion molecule-1; IL-1 $\beta$, interleukin-1 $\beta$; cTnI, cardiac troponin I; $\alpha$-MHC, $\alpha$-myosin heavy chain; ELISA, enzyme-linked immunosorbent assay; AMI, acute myocardial infarction; BMSC, bone marrow mesenchymal stem cell; NC, negative control; BUTMD, BMSCs + UTMD.

with UTMD-mediated Galectin-7-siRNA exhibited improved cardiac function and left ventricular hemodynamics-related indices, as well as decreased myocardial fiber damage, myocardial infarct size and apoptotic cells. UTMD could be a potential tailored therapy used to induce cardiac regeneration following an extensive infarct, which is able to deliver repeated regimens until ventricular function and myocardial perfusion have been restored (40). A previous study demonstrated that systemic administration of UTMD can improve the targeted gene transfer to the heart (41). Furthermore, increasing evidence has indicated that UTMD increases the migration of BMSCs to the injured kidney and infarcted myocardium $(42,43)$. In addition, UTMD has also been found to result in microvascular rupture in target organs, leading to the enhancement of certain cytokines, and elevated BMSC migration into the heart and kidney (44-46). It has been reported that overexpression of CXCR-4 combined with UTMD could significantly augment the homing ability of BMSCs (43). Another study revealed that UTMD combined with other non-viral vectors could improve gene transfection efficiency and protect the multi-directional differentiation and reproductive ability of the transfected BMSCs (47). Some articles have elucidated that SDF-1 and VCAM-1 expression is implicated in the liver homing of BMSCs (48-50). Recently, it has been revealed that increased VCAM-1 expression indicates that UTMD may induce BMSC migration by enhancing interstitial and intercellular capillary permeability (51). Furthermore, when the UTMD procedure is performed following a pre-injection of BMSCs, or when 


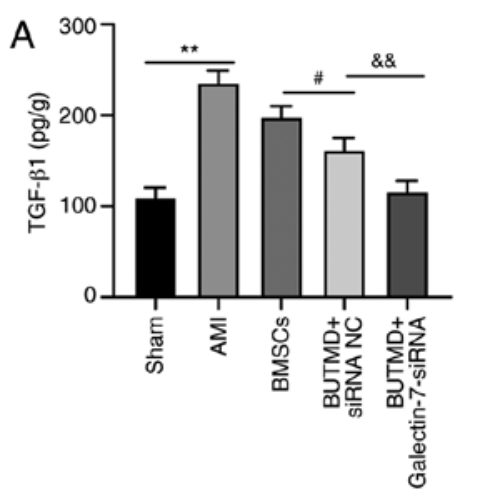

B

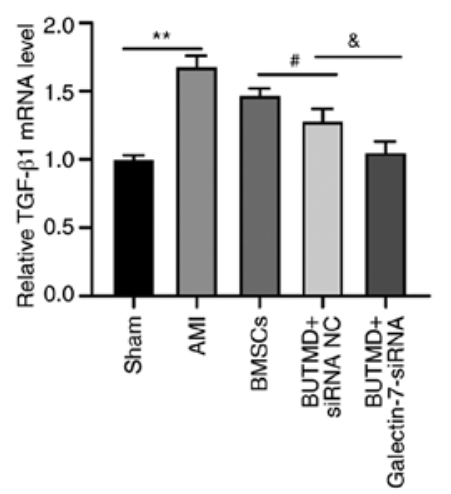

- Sham $\square$ AMI $\square$ BMSCs

$\square$ BUTMD+siRNA NC

2.07 BUTMD+Galectin-7-siRNA

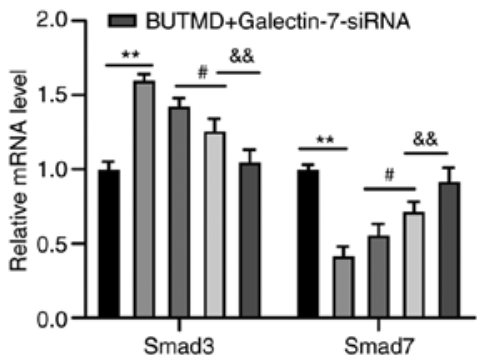

C
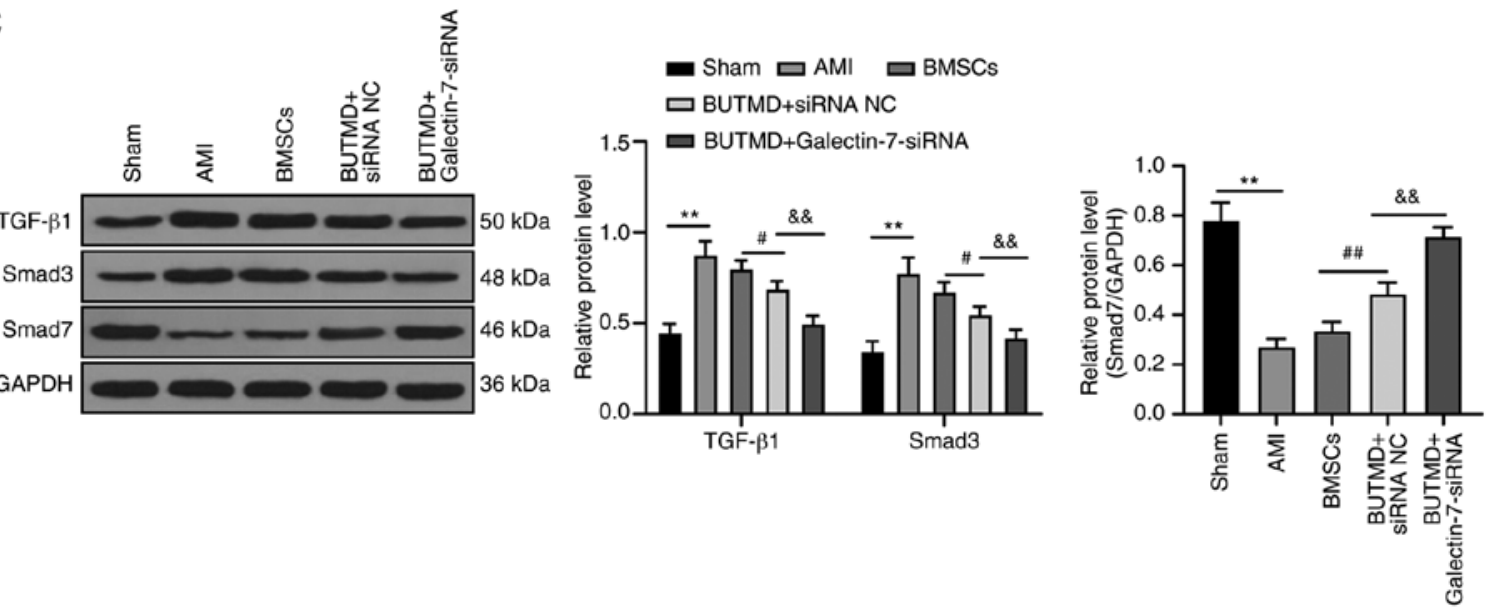

Figure 5. UTMD-mediated Galectin-7-siRNA suppresses the TGF- $\beta /$ Smads signaling pathway. (A) Detection of TGF- $\beta 1$ in myocardial tissue homogenate using ELISA. (B) Reverse transcription-quantitative PCR was performed to detect mRNA expression levels of TGF- $\beta 1$, Smad3 and Smad7. (C) Western blotting was conducted to detect the protein expression levels of TGF- $\beta 1$, Smad3 and Smad7 (n=6/group). Data in panels A, B (left) and C (right) were analyzed using one-way ANOVA, and data in panels B (right) and C (left) were analyzed using two-way ANOVA, followed by Tukey's multiple comparisons test. ${ }^{* *} \mathrm{P}<0.01 ;{ }^{\#} \mathrm{P}<0.05$ and ${ }^{\# \#} \mathrm{P}<0.01 ;{ }^{\&} \mathrm{P}<0.05$ and ${ }^{\& \&} \mathrm{P}<0.01$. UTMD, ultrasound-targeted microbubble destruction; TGF- $\beta 1$, transforming growth factor- $\beta 1$; siRNA, small interfering RNA; ELISA, enzyme-linked immunosorbent assay; AMI, acute myocardial infarction; BMSC, bone marrow mesenchymal stem cell; NC, negative control; BUTMD, BMSCs + UTMD.

UTMD is combined with BMSC transplantation, there is a beneficial effect on the engraftment of cells $(52,53)$. Ultrasound microbubbles can enhance the therapeutic effect of BMSCs in diseases and promote BMSC homing $(51,54,55)$. In the present study, the BUTMD + siRNA NC group had an intermediate therapeutic effect. The present study contributes towards our knowledge of the ability of Galectin-7 in AMI or the combination of Galectin-7 with UTMD in MI, however this topic deserves further in-depth exploration in order to be applied to the clinic. Galectin-3, another member of Galectin family, is mainly secreted by activated macrophages, which has been established as a prognostic target in various heart failure cohorts (56). Galectin-3 has been found to be implicated in heart failure and predicts enhanced mortality and morbidity in heart failure. Heart failure often develops after MI, and contributes to worse outcomes (56). TGF- $\beta / \mathrm{Smad}$ is a critical pathway that modulates damage-induced and programmed senescence (57). The TGF- $\beta /$ Smads pathway may be implicated in the reconstruction of MI scars through continuous stimulation of matrix deposition (58). Xinfuli Granule has been demonstrated to ameliorate ventricular remodeling and myocardial fibrosis after $\mathrm{MI}$ in rats via modulation of the TGF- $\beta$ /Smad pathway (59). Moreover, a previous study revealed that Galectin- 7 can inhibit the TGF- $\beta / S m a d 3$ pathway to promote the proliferation of activated $\mathrm{CD} 4^{+} \mathrm{T}$ cells (19). BMSCs can improve spinal cord function in rats with spinal cord injury via the TGF- $\beta /$ Smads pathway (60). The present study showed that the levels of TGF- $\beta 1$ and Smad3 in myocardial tissue homogenate were reduced in rats treated with UTMD-mediated Galectin-7-siRNA. Thus, these results suggested that UTMD-mediated Galectin-7-siRNA treatment could improve AMI in rat via inhibiting the TGF- $\beta / \mathrm{Smads}$ pathway.

In summary, the present study suggested that UTMD-mediated Galectin-7-siRNA treatment enhanced the homing ability of BMSCs, improved myocardial microenvironment, and inhibited the TGF- $\beta /$ Smads signaling pathway to alleviate AMI in rats. The advancement of BMSC homing ability is vital for effective clinical application, however further studies are needed to evaluate its safety and efficacy. It is often difficult to achieve the desired therapeutic effect with siRNA treatment alone as siRNA is prone to degrade in vivo, so microbubbles are used to protect the structure of siRNA. UTMD can promote siRNA targeting into pathological tissues 
and thus play a role in gene intervention. Therefore, there was not an siRNA group used in this study. In the future, relevant research will be performed to verify the effect of UTMD Galectin-7 siRNA treatment alone in order to improve the reliability of these conclusions.

\section{Acknowledgements}

Not applicable.

\section{Funding}

This study was supported by the Youth Fund in Guizhou Provincial People's Hospital [grant no. GZSYQN2018(02)] and the Clinical Research Center Project of Department of Science and Technology of Guizhou Province [grant no. (2017)5405].

\section{Availability of data and materials}

All data generated or analyzed during this study are included in this published article.

\section{Authors' contributions}

$\mathrm{XW}, \mathrm{JT}, \mathrm{HZ}$ are the guarantors of integrity of the entire study. $\mathrm{JT}$ and $\mathrm{HZ}$ contributed to the conception and design of the present study, and definition of intellectual content. XW and WZ contributed to the literature research. XW, YZ and WZ performed experimental studies and data acquisition. XW and $\mathrm{YZ}$ contributed to the analysis of data and prepared the manuscript. XW performed the statistical analyses. XW, YZ and JT contributed to the manuscript editing. JT and HZ contributed to the manuscript review. All authors read and approved the final manuscript.

\section{Ethics approval and consent to participate}

Animal experiments were performed in accordance with the Guide to the Management and Use of Laboratory Animals (22). The animal experiments were approved by the Institutional Animal Care and Use Committee of People's Hospital of Deyang City (approval no. 20190075; Deyang, China).

\section{Patient consent for publication}

Not applicable.

\section{Competing interests}

The authors declare that they have no competing interests.

\section{References}

1. Ghartavol MM, Gholizadeh-Ghaleh S, Babaei G, Farjah GH and Ansari MH: The protective impact of betaine on the tissue structure and renal function in isoproterenol-induced myocardial infarction in rat. Mol Genet Genomic Med 7: e00579, 2019.

2. Yang S, Fan T, Hu Q, Xu W, Yang J, Xu C, Zhang B, Chen J and Jiang H: Downregulation of microRNA-17-5p improves cardiac function after myocardial infarction via attenuation of apoptosis in endothelial cells. Mol Genet Genomics 293: 883-894, 2018.
3. Yang J, Brown ME, Zhang H, Martinez M, Zhao Z, Bhutani S, Yin S, Trac D, Xi JJ and Davis ME: High-Throughput screening identifies microRNAs that target nox 2 and improve function after acute myocardial infarction. Am J Physiol Heart Circ Physiol 312: H1002-H1012, 2017.

4. Lu C, Wang X, Ha T, Hu Y, Liu L, Zhang X, Yu H, Miao J, Kao R, Kalbfleisch J, et al: Attenuation of cardiac dysfunction and remodeling of myocardial infarction by microRNA-130a are mediated by suppression of PTEN and activation of PI3K dependent signaling. J Mol Cell Cardiol 89: 87-97, 2015.

5. Vignoli A, Tenori L, Giusti B, Takis PG, Valente S, Carrabba N, Balzi D, Barchielli A, Marchionni N, Gensini GF, et al: NMR-Based metabolomics identifies patients at high risk of death within two years after acute myocardial infarction in the AMI-Florence II cohort. BMC Med 17: 3, 2019.

6. He JG, Li HR, Li BB, Xie QL, Yan D and Wang XJ: Bone marrow mesenchymal stem cells overexpressing GATA-4 improve cardiac function following myocardial infarction. Perfusion 34: 696-704, 2019.

7. Chen S and Grayburn PA: Ultrasound-Targeted microbubble destruction for cardiac gene delivery. Methods Mol Biol 1521: 205-218, 2017.

8. Jayasankar V, Woo YJ, Bish LT, Pirolli TJ, Chatterjee S, Berry MF, Burdick J, Gardner TJ and Sweeney HL: Gene transfer of hepatocyte growth factor attenuates postinfarction heart failure. Circulation 108: II230-II236, 2003.

9. Yau TM, Fung K, Weisel RD, Fujii T, Mickle DA and Li RK: Enhanced myocardial angiogenesis by gene transfer with transplanted cells. Circulation 104: I218-I222, 2001.

10. Sun W, Li Z, Zhou X, Yang G and Yuan L: Efficient exosome delivery in refractory tissues assisted by ultrasound-targeted microbubble destruction. Drug Deliv 26: 45-50, 2019.

11. Fujii H, Sun Z, Li SH, Wu J, Fazel S, Weisel RD, Rakowski H, Lindner $\mathrm{J}$ and Li RK: Ultrasound-Targeted gene delivery induces angiogenesis after a myocardial infarction in mice. JACC Cardiovasc Imaging 2: 869-879, 2009.

12. Hernot S, Cosyns B, Droogmans S, Garbar C, Couck P, Vanhove C, Caveliers V, Van Camp G, Bossuyt A and Lahoutte T: Effect of high-intensity ultrasound-targeted microbubble destruction on perfusion and function of the rat heart assessed by pinhole-gated SPECT. Ultrasound Med Biol 36: $158-165,2010$.

13. Karetnikova V, Osokina A, Gruzdeva O, Uchasova E, Zykov M, Kalaeva V, Kashtalap V, Shafranskaya K, Hryachkova O and Barbarash O: Serum galectin and renal dysfunction in ST-segment elevation myocardial infarction. Dis Markers 2016: $1549063,2016$.

14. Advedissian T, Deshayes F and Viguier M: Galectin-7 in epithelial homeostasis and carcinomas. Int J Mol Sci 18: 2017.

15. Saussez S and Kiss R: Galectin-7. Cell Mol Life Sci 63: 686-697, 2006.

16. Chen HL, Chiang PC, Lo CH, Lo YH, Hsu DK, Chen HY and Liu FT: Galectin-7 regulates keratinocyte proliferation and differentiation through JNK-miR-203-p63 signaling. J Invest Dermatol 136: 182-191, 2016.

17. Al-Salam $S$ and Hashmi S: Galectin-1 in early acute myocardial infarction. PLoS One 9: e86994, 2014.

18. Shirakawa K, Endo J, Kataoka M, Katsumata Y, Yoshida N, Yamamoto T, Isobe S, Moriyama $\mathrm{H}$, Goto S, Kitakata $\mathrm{H}$, et al: IL (Interleukin)-10-STAT3-Galectin-3 ax is is essential for osteopontin-producing reparative macrophage polarization after myocardial infarction. Circulation 138: 2021-2035, 2018.

19. Luo Z, Ji Y, Tian D, Zhang Y, Chang S, Yang C, Zhou H and Chen ZK: Galectin-7 promotes proliferation and Th1/2 cells polarization toward Th1 in activated $\mathrm{CD} 4^{+} \mathrm{T}$ cells by inhibiting The TGF $\beta /$ Smad3 pathway. Mol Immunol 101: 80-85, 2018.

20. Villeneuve C, Baricault L, Canelle L, Barboule N, Racca C, Monsarrat B, Magnaldo T and Larminat F: Mitochondrial proteomic approach reveals galectin-7 as a novel BCL-2 binding protein in human cells. Mol Biol Cell 22: 999-1013, 2011.

21. Tran BH, Yu Y, Chang L, Tan B, Jia W, Xiong Y, Dai T, Zhong R, Zhang W, Le VM, et al: A novel liposomal S-propargyl-cysteine: A sustained release of hydrogen sulfide reducing myocardial fibrosis via TGF-beta1/smad Pathway. Int J Nanomedicine 14: 10061-10077, 2019.

22. Guide for the Care and Use of Laboratory Animals: National Research Council (US) Committee for the Update of the Guide for the Care and Use of Laboratory Animals. 8th edition. National Academies Press, Washington, DC, 2011. 
23. Lu D, Liao Y,Zhu SH, Chen QC, Xie DM, Liao JJ,Feng X, Jiang MH and He W: Bone-Derived nestin-positive mesenchymal stem cells improve cardiac function via recruiting cardiac endothelial cells after myocardial infarction. Stem Cell Res Ther 10: 127, 2019.

24. Olivetti G, Capasso JM, Meggs LG, Sonnenblick EH and Anversa P: Cellular basis of chronic ventricular remodeling after myocardial infarction in rats. Circ Res 68: 856-869, 1991.

25. Zatroch KK, Knight CG, Reimer JN and Pang DS: Refinement of intraperitoneal injection of sodium pentobarbital for euthanasia in laboratory rats (Rattus norvegicus). BMC Vet Res 13: 60, 2017.

26. Livak KJ and Schmittgen TD: Analysis of relative gene expression data using real-time quantitative PCR and the 2(-Delta Delta $\mathrm{C}(\mathrm{T})$ ) method. Methods 25: 402-408, 2001.

27. Nguyen PK, Rhee JW and Wu JC: Adult stem cell therapy and heart failure, 2000 to 2016: A systematic review. JAMA Cardiol 1: 831-841, 2016.

28. Chen Z, Zeng C and Wang WE: Progress of stem cell transplantation for treating myocardial infarction. Curr Stem Cell Res Ther 12: 624-636, 2017.

29. Mangi AA, Noiseux N, Kong D, He H, Rezvani M, Ingwall JS and Dzau VJ: Mesenchymal stem cells modified with akt prevent remodeling and restore performance of infarcted hearts. Nat Med 9: 1195-1201, 2003.

30. Leung VY, Aladin DM, Lv F, Tam V, Sun Y, Lau RY, Hung SC, Ngan AH, Tang B, Lim CT, et al: Mesenchymal stem cells reduce intervertebral disc fibrosis and facilitate repair. Stem Cells 32 2164-2177, 2014

31. Li D, Wang N, Zhang L, Hanyu Z, Xueyuan B, Fu B, Shaoyuan C, Zhang W, Xuefeng S, Li R and Chen X: Mesenchymal stem cells protect podocytes from apoptosis induced by high glucose via secretion of epithelial growth factor. Stem Cell Res Ther 4: 103, 2013.

32. Liu H, Liu S, Li Y, Wang X, Xue W, Ge G and Luo X: The role of SDF-1-CXCR4/CXCR7 axis in the therapeutic effects of hypoxia-preconditioned mesenchymal stem cells for renal ischemia/reperfusion injury. PLoS One 7: e34608, 2012.

33. Ryu CH, Park SA, Kim SM, Lim JY, Jeong CH, Jun JA, Oh JH, Park SH, Oh WI and Jeun SS: Migration of human umbilical cord blood mesenchymal stem cells mediated by stromal cell-derived factor-1/CXCR4 axis via akt, ERK, and p38 signal transduction pathways. Biochem Biophys Res Commun 398: 105-110, 2010.

34. Gul-Uludag $\mathrm{H}$, Xu P, Marquez-Curtis LA, Xing J Janowska-Wieczorek A and Chen J: Cationic liposome-mediated CXCR4 gene delivery into hematopoietic stem/progenitor cells: Implications for clinical transplantation and gene therapy. Stem Cells Dev 21: 1587-1596, 2012.

35. Deak E, Seifried E and Henschler R: Homing pathways of mesenchymal stromal cells (MSCs) and their role in clinical applications. Int Rev Immunol 29: 514-529, 2010.

36. Karp JM and Teo GS: Mesenchymal stem cell homing: The devil is in the details. Cell Stem Cell 4: 206-216, 2009.

37. Chamberlain G, Wright K, Rot A, Ashton B and Middleton J: Murine mesenchymal stem cells exhibit a restricted repertoire of functional chemokine receptors: Comparison with human. PLoS One 3: e2934, 2008

38. Li L and Jiang J: Regulatory factors of mesenchymal stem cell migration into injured tissues and their signal transduction mechanisms. Front Med 5: 33-39, 2011.

39. Lotfinegad P, Shamsasenjan K, Movassaghpour A, Majidi J and Baradaran B: Immunomodulatory nature and site specific affinity of mesenchymal stem cells: A hope in cell therapy. Adv Pharm Bull 4: 5-13, 2014

40. Fujii H, Li SH, Wu J, Miyagi Y, Yau TM, Rakowski H, Egashira K, Guo J, Weisel RD and Li RK: Repeated and targeted transfer of angiogenic plasmids into the infarcted rat heart via ultrasound targeted microbubble destruction enhances cardiac repair. Eur Heart J 32: 2075-2084, 2011

41. Yang SL, Mu YM, Tang KQ, Jiang XK, Bai WK, Shen E and $\mathrm{Hu} \mathrm{B}$ : Enhancement of recombinant adeno-associated virus mediated transgene expression by targeted echo-contrast agent. Genet Mol Res 12: 1318-1326, 2013

42. Imada T, Tatsumi T, Mori Y, Nishiue T, Yoshida M, Masaki H, Okigaki M, Kojima H, Nozawa Y, Nishiwaki Y, et al: Targeted delivery of bone marrow mononuclear cells by ultrasound destruction of microbubbles induces both angiogenesis and arteriogenesis response. Arterioscler Thromb Vasc Biol 25: 2128-2134, 2005.

43. Wang G, Zhang Q, Zhuo Z, Wu S, Xu Y, Zou L, Gan L, Tan K Xia H, Liu Z and Gao Y: Enhanced homing of CXCR-4 modified bone marrow-derived mesenchymal stem cells to acute kidney injury tissues by micro-bubble-mediated ultrasound exposure. Ultrasound Med Biol 42: 539-548, 2016.
44. Enomoto S, Yoshiyama M, Omura T, Matsumoto R, Kusuyama T, Nishiya D, Izumi Y, Akioka K, Iwao H, Takeuchi K and Yoshikawa J: Microbubble destruction with ultrasound augments neovascularisation by bone marrow cell transplantation in rat hind limb ischaemia. Heart 92: 515-520, 2006.

45. Wu S, Li L, Wang G, Shen W, Xu Y, Liu Z, Zhuo Z, Xia H, Gao Y and Tan K: Ultrasound-Targeted stromal cell-derived factor-1-loaded microbubble destruction promotes mesenchymal stem cell homing to kidneys in diabetic nephropathy rats. Int J Nanomedicine 9: 5639-5651, 2014.

46. Zhong S, Shu S, Wang Z, Luo J, Zhong W, Ran H, Zheng Y, Yin Y and Ling Z: Enhanced homing of mesenchymal stem cells to the ischemic myocardium by ultrasound-targeted microbubble destruction. Ultrasonics 52: 281-286, 2012.

47. Li P, Gao Y, Liu Z, Tan K, Zuo Z, Xia H, Yang D, Zhang Y and Lu D: DNA transfection of bone marrow stromal cells using microbubble-mediated ultrasound and polyethylenimine: An in vitro study. Cell Biochem Biophys 66: 775-786, 2013.

48. Belema-Bedada F, Uchida S, Martire A, Kostin S and Braun T: Efficient homing of multipotent adult mesenchymal stem cells depends on FROUNT-mediated clustering of CCR2. Cell Stem Cell 2: 566-575, 2008.

49. Kuo TK, Hung SP, Chuang CH, Chen CT, Shih YR, Fang SC, Yang VW and Lee OK: Stem cell therapy for liver disease: Parameters governing the success of using bone marrow mesenchymal stem cells. Gastroenterology 134: 2111-2121, 2008.

50. Togel FE and Westenfelder C: Role of SDF-1 as a regulatory chemokine in renal regeneration after acute kidney injury. Kidney Int Suppl 2011: 87-89, 2011.

51. Sun T, Gao F, Li X, Cai Y, Bai M, Li F and Du L: A combination of ultrasound-targeted microbubble destruction with transplantation of bone marrow mesenchymal stem cells promotes recovery of acute liver injury. Stem Cell Res Ther 9: 356, 2018.

52. Li L, Wu S, Li P, Zhuo L, Gao Y and Xu Y: Hypoxic preconditioning combined with microbubble-mediated ultrasound effect on MSCs promote SDF-1/CXCR4 expression and its migration ability: An in vitro study. Cell Biochem Biophys 73: 749-757, 2015.

53. Zhang Y, Ye C, Wang G, Gao Y, Tan K, Zhuo Z, Liu Z, Xia H, Yang D and Li P: Kidney-targeted transplantation of mesenchymal stem cells by ultrasound-targeted microbubble destruction promotes kidney repair in diabetic nephropathy rats. Biomed Res Int 2013: 526367, 2013.

54. Wang G, Zhang Q, Zhuo Z, Wu S, Liu Z, Xia H, Tan K, Zou L, Gan L and Gao Y: Effects of diagnostic ultrasound-targeted microbubble destruction on the homing ability of bone marrow stromal cells to the kidney parenchyma. Eur Radiol 26: 3006-3016, 2016.

55. Qian J, Wang L, Li Q, Sha D, Wang J, Zhang J, Xu P and Fan G: Ultrasound-Targeted microbubble enhances migration and therapeutic efficacy of marrow mesenchymal stem cell on rat middle cerebral artery occlusion stroke model. J Cell Biochem 120: 3315-3322, 2019.

56. Szadkowska I, Wlazeł RN, Migała M, Szadkowski K, Zielińska M, Paradowski M and Pawlicki L: The association between galectin-3 and clinical parameters in patients with first acute myocardial infarction treated with primary percutaneous coronary angioplasty. Cardiol J 20: 577-582, 2013.

57. Lyu G, Guan Y, Zhang C, Zong L, Sun L, Huang X, Huang L, Zhang L, Tian XL, Zhou Z and Tao W: TGF-Beta signaling alters H4K20me3 status via miR-29 and contributes to cellular senescence and cardiac aging. Nat Commun 9: 2560, 2018

58. Hao J, Ju H, Zhao S, Junaid A, Scammell-La Fleur T and Dixon IM: Elevation of expression of smads 2,3, and 4, decorin and TGF-beta in the chronic phase of myocardial infarct scar healing. J Mol Cell Cardiol 31: 667-678, 1999.

59. Ma J, Li ZY, Liang XP, Guo CX, Lu PP and Ma LH: Xinfuli granule improves post-myocardial infarction ventricular remodeling and myocardial fibrosis in rats by regulating TGF- $\beta /$ smads signaling pathway. J Geriatr Cardiol 14: 301-307, 2017.

60. Lv C, Zhang T, Li K and Gao K: Bone marrow mesenchymal stem cells improve spinal function of spinal cord injury in rats via TGF- $\beta /$ smads signaling pathway. Exp Ther Med 19: 3657-3663, 2020.

This work is licensed under a Creative Commons Attribution-NonCommercial-NoDerivatives 4.0 International (CC BY-NC-ND 4.0) License. 